\title{
Sistem Aplikasi Kamus Istilah Bahasa Pemrograman PHP Menggunakan Algoritma Brute Force
}

\section{Application System Dictionary of PHP Programming Language Terms Using Brute Force Algorithm}

\author{
Bayu Erdani ${ }^{1}$, Fredy Dwi Aditia ${ }^{2}$, Siti Rodiah $^{3}$, Ciptyasih $^{4}$, Indyah Hartami Santi \\ Program Studi Teknik Informatika, Fakultas Teknologi Informasi, Universitas Islam Balitar, \\ J1. Majapahit No. 4 Blitar Jawa Timur 66133, Indonesia \\ Email: bayuerdani99@gmail.com, aditiafredy@gmail.com, sitirodiyah528@gmail.com, \\ ciptytyas@gmail.com, indyahartamisanti@gmail.com
}

\begin{abstract}
ABSTRAK
Kamus merupakan alat bantu yang digunakan untuk menterjemahkan suatu bahasa, adapun terdapat berbagai jenis kamus seperti kamus istilah Bahasa pemrograman PHP. Bahasa pemrograman PHP pada dasarnya penting bagi para mahasiswa yang sedang menempuh pembelajaran mengenai bahasa pemrograman khususnya PHP, terutama istilah dalam bahasa pemrograman PHP yang memilik banyak kosa kata. Penelitian dilakukan untuk dapat merancang suatu aplikasi kamus istilah dalam bahasa pemrograman PHP dengan menggunakan algoritma brute force dalam proses pencariannya. Algoritma brute force merupakan algoritma yang digunakan untuk mencocokan pattern dengan semua teks yang ada pada database aplikasi kamus istilah bahasa pemrograman PHP. Dalam penelitian ini metode pengembangan sistem yang digunakan yaitu model prototype dan perangkat lunak pendukung yang digunakan adalah Microsoft SQL Server. Adapun hasil akhir dari penelitian ini yakni berupa aplikasi kamus istilah bahasa pemrograman PHP dengan menggunakan algoritma brute force dalam proses pencariannya dan dapat membantu pengguna untuk mencari istilah kata menjadi lebih efisen dibandingkan kamus berbentuk buku pada umumnya.
\end{abstract}

Kata Kunci: Algoritma Brute Force; kamus istilah; pemrograman PHP

\begin{abstract}
Dictionary is a tool that is used to interpret a language, while there are various types of dictionaries such as dictionary terms PHP programming language. PHP programming language is basically important for students who are learning about programming languages, especially PHP, especially the terms in the PHP programming language that has a lot of vocabulary. The research was conducted to be able to design a term dictionary application in the PHP programming language using the brute force algorithm in the search process. The brute force algorithm is an algorithm that is used to match patterns with all the text in the dictionary database application terms of the PHP programming language. In this study the system development method used is the prototype model and the supporting software used is Microsoft SQL Server. The final results of this study are in the form of a dictionary application term PHP programming language using the brute force algorithm in the search process and can help users to search for the term word to be more efficient than a dictionary in the form of books in general
\end{abstract}

Keywords: Brute Force Algorithm; dictionary term; PHP programming

\section{PENDAHULUAN}

Kamus merupakan media yang dapat mengartikan suatu kata dari Bahasa atau Bahasa asing. Sebagai contoh kamus yang berisikan istilah-istilah Bahasa pemrogaman php, maka tersebut akan membahas istilah Bahasa pemrograman php. Dalam istilah bahasa pemrogaman php, terdapat banyak istilah yang menjadikan user kesulitan untuk menghafalnya, 
oleh karena itu perlu adanya sebuah kamus istilah bahasa pemrograman php untuk mempermudah sistem pengolahan basis data atau database. Pengolahan database yang berisikan istilah-istilah Bahasa pemrograman php diharapkan dapat diketahui oleh setiap mahasiswa yang membutuhkannya. Saat ini masih belum ada penggunaan kamus yang berbentuk website untuk memperoleh informasi khususnya tentang istilah-istilah Bahasa pemrograman php.

Sistem informasi Kamus Istilah Bahasa Pemrograman Php Berbasis Web yang dibangun ini menggunakan metode Brute Force. Metode Brute Force adalah salah satu algoritma pemecahan masalah dengan strategi solusi langsung (Direct Solution Strategies). Cara kerja algoritma ini adalah dengan mencoba setiap posisi pattern (kata yang akan dicocokkan) terhadap teks, kemudian dilakukan proses pencocokkan setiap karakter dan teks pada posisi tersebut, Sehingga sangat kecil kemungkinan pattern yang dicari akan terlewat, Di sistem aplikasi kamus ini, data-data istilah disimpan dalam database, data akan di tampilkan sesuai dengan data inputan user secara otomatis dengan metode Brute Force.

Sistem aplikasi ini dibangun dengan maksud untuk menambah pengetahuan dan wawasan terhadap mahasiswa tentang kamus istilah Bahasa pemrograman php yang berbasis website. Aplikasi ini berisi istilah - istilah dan deskripsi Bahasa pemrograman php yang disajikan dengan desain yang menarik dengan harapan dapat membantu mahasiswa dalam mencari pengetahuan dan wawasan tentang istilah Bahasa pemrograman karena dengan aplikasi ini mahasiswa lebih mudah dan lebih efisien untuk mencarinya. Dikarenakan satu aplikasi bisa digunakan banyak orang dalam berbagai tempat.

\section{TINJAUAN PUSTAKA \\ 2.1 Kamus}

Menurut Hoetomo M.A (2005) mendefinisikan, kamus yaitu buku acuan yang memuat kata dan ungkapan yang biasanya disusun menurut abjad berikut keterangan dan maknanya. Dari definisi kamus di atas dapat disimpulkan bahwa kamus merupakan buku yang membuat kumpulan istilah atau namanama yang disusun beserta penjelasannya tentang pemakaiannya, disusun menurut abjad berikut keterangan maknanya, atau terjemahannya dari istilah atau nama-nama tersebut.

\subsection{Bahasa Pemrograman PHP}

Menurut Sibero (2011) PHP adalah pemrograman interpreter yaitu proses penerjemahan baris kode sumber menjadi kode mesin yang dimengerti komputer secara langsung pada saat baris kode dijalankan. Php disebut juga pemrograman Server Side Programming, hal ini dikarenakan seluruh prosesnya dijalankan pada server. PHP adalah suatu bahasa dengan hak cipta terbuka atau yang juga dikenal dengan open source yaitu pengguna data mengembangkan kode-kode fungsi sesuai kebutuhannya.

Menurut Arief (2011) PHP adalah bahasa server side scripting yang menyatu dengan HTML untuk membuat halaman web yang dinamis. Menurut Aditya (2011) "PHP adalah bahasa skrip yang dapat ditanamkan atau disisipkan ke dalam HTML. PHP banyak dipakai untuk memprogram situs web dinamis. Kelebihan Bahasa pemrogaman php diantaranya: (jhonnie fadillah, 2017)

a. PHP dapat diakses dengan gratis tanpa mengeluarkan uang sedikitpun.

b. PHP bersifat open source sehingga dapat dikembangkan php sesuai dengan kreasi kita sendiri

c. Multiplatform, cocok digunakan di semua komputer dan semua Operating System

d. Cocok digabungkan dengan berbagai macam database seperti MySQL

e. PostgreSQL, MySQLi, dan sebagainya.

f. Tidak memerlukan deklarasi Variable seperti program pascal dan sebagainya.

g. PHP tidak memerlukan konektor seperti java, PHP bisa langsung mengakses database. Sedangkan kekurangannya sebagai berikut:

a. PHP tidak mengenal Encoding

b. PHP memiliki kekurangan security tertenu jika para web programmer tidak teliti

c. Untuk menggunakannya, harus menginstal web server terlebih dahulu

d. Tidak bisa memisahkan antara tampilan dan logic (meskipun sekarang pembuatan template lebih cendrung menggunakan html, css, dan javascript).

\subsection{Algoritma Brute Force}

Algoritma brute force adalah algoritma yang digunakan untuk mencocokan pattern dengan semua teks antara 0 dan $n-m$ untuk 
menemukan keberadaan Pattern teks. Algoritma brute force memecahkan masalah dengan sangat sederhana, langsung, dan jelas. Algortima brute-force merupakan suatu teknik yang biasa digunakan bila si penyusun algoritma lebih mempertimbangkan memperoleh solusi dari problem secara langsung apa adanya Secara rinci langkahlangkah yang digunakan algoritma brute force untuk mencocokkan string adalah, sebagai berikut: (Sarno, 2012).

a. Algoritma brute force mulai mencocokan pattern dari awal teks.

b. Dari kiri ke kanan, algoritma brute force akan mencocokan karakter per karakter pattern dengan karakter pada teks yang bersesuaian, sampai salah satu kondisi berikut terpenuhi :

c. Karakter di pattern yang dibandingkan cocok maka pencarian selesai.

d. Apabila dijumpai ketidak cocokan antara pattern dengan teks, maka pencarian tidak cocok dan belum berhasil.

e. Algoritma brute force terus menggeser pattern sebesar satu ke kanan, dan mengulangi langkah ke-2 sampai pattern berada di ujung teks.

Menurut Mesran (2014) algoritma brute force juga memiliki kelebihan dan kelemahan. Adapun kelebihan Algoritma brute force yaitu :

a. Algoritma brute force dapat digunakan untuk memecahkan hampir sebagian besar masalah.

b. Algoritma brute force sederhana dan mudah dimengerti.

c. Algoritma brute force menghasilkan algoritma yang ayak untuk beberpa masalah penting seperti pencarian, pengurutan, pencocokkan, string atau perkaian matriks.

d. Algoritma brute force menghasilkan algoritma baku (standart) untuk tugastugas komputasi penjumlahan/perkaian $\mathrm{n}$ buah bilangan, menentukan elemen minimum atau maksimum di dalam tabel (list).

Sedangkan kelemahan dari algoritma brute force yaitu sebagi berikut :

a. Algoritma brute force jarang menghasilkan algoritma yang mangkus (manjur).

b. Beberapa algoritma brute force lambat, sehingga tidak dapat diterima.

c. Tidak sekonstruktif (sekreatif) teknik pemecahan masalah lainnya.

\section{METODOLOGI PENELITIAN}

\subsection{Pengumpulan Data}

a. Survei, mengumpulkan data dengan cara mengadakan pengaman secara langsung ke mahasiswa Universitas Islam Balitar Blitar dan pencatatan hal-hal yang perlu disusun dalam laporan.

b. Wawancara, dengan melakukan tanya jawab secara lisan antara dua orang atau lebih kepada Mahasiswa Universitas Islam Balitar Blitar sehingga dapat menerima informasi yang akurat.

c. Literatur, pengumpulan data melalui berbagai sumber seperti buku, jurnal. Data yang diambil meliputi konsep dasar yang melandasi landasan dasar teori penulis.

\subsection{Analisa Data dan Kebutuhan}

a. Data Istilah, yang dibutuhkan sesuai data Istilah yang terdapat pada bahasa pemrograman PHP.

b. Bentuk Konsep Kamus, yang dibutuhkan untuk menempatkan data Istilah yaitu menggunakan konsep Kamus.

\subsection{Perancangan Algoritma}

Perancangan dilakukan untuk membuat sistem yang baik. Perancangan ini dilakukan untuk mendapat gambaran yang jelas mengenai aplikasi yang dibangun. Alur tahapan algoritma Brute force terlihat seperti pada gambar 1. 


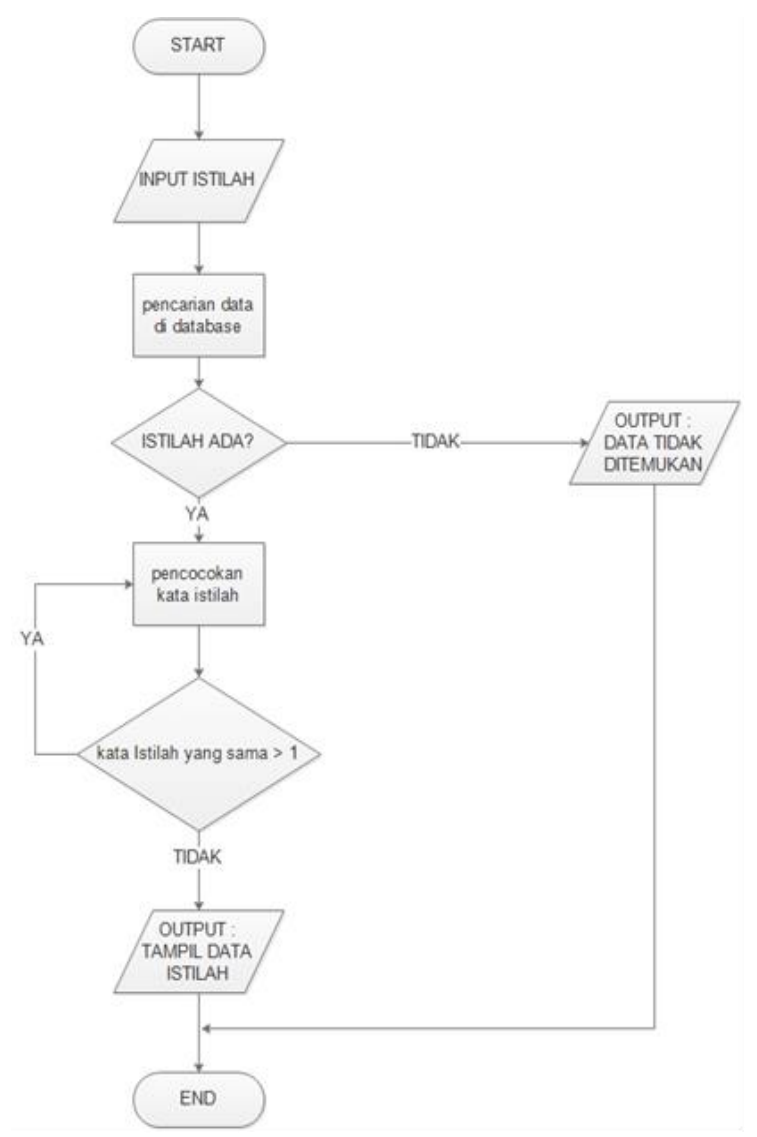

Gambar 1. Alur Algoritma brute force

\section{PEMBAHASAN}

\subsection{Algoritma Brute Force}

Langkah-langkah penerapan algoritma brute force pada sistem aplikasi kamus istilah bahasa pemrograman PHP ini dimulai dari pencarian pattern dalam teks, misalnya teks : DATABASE MYSQL dengan Pattern = $M Y S Q L$. Langkah awal pelacakan algoritma seperti terlihat pada tabel 1 .

Tabel 1. Penggunaan algoritma brute force langkah-1

\begin{tabular}{|c|c|c|c|c|c|c|c|c|c|c|c|c|c|}
\hline \multicolumn{14}{|c|}{ Langkah Ke-1 } \\
\hline Text & D & A & $\mathrm{T}$ & A & B & A & $S$ & $\mathrm{E}$ & $\mathrm{M}$ & $\mathrm{Y}$ & $S$ & Q & $\mathrm{L}$ \\
\hline Pattern & $\mathrm{M}$ & $Y$ & $S$ & $\mathrm{Q}$ & $\mathrm{L}$ & & & & & & & & \\
\hline Indeks & 1 & 2 & 3 & 4 & 5 & 6 & 7 & 8 & 10 & 11 & 12 & 13 & 14 \\
\hline
\end{tabular}

Hasil langkah pertama pada tabel 1 diperoleh hasil tidak cocok, sehingga algoritma menggeser pattern sebanyak satu langkah ke kanan menuju indek berikutnya, seperti pada tabel 2 :

Tabel 2. Penggunaan algoritma brute force langkah-2

\begin{tabular}{|c|c|c|c|c|c|c|c|c|c|c|c|c|c|c|}
\hline Langka & & & & & & & & & & & & & & \\
\hline Text & D & A & $\mathrm{T}$ & A & B & A & $S$ & E & & M & Y & $S$ & Q & $\mathrm{L}$ \\
\hline Pattern & & M & $\mathrm{Y}$ & $\mathrm{S}$ & Q & $\mathrm{L}$ & & & & & & & & \\
\hline Indeks & 1 & 2 & 3 & 4 & 5 & 6 & 7 & 8 & 9 & 10 & 11 & 12 & 13 & 14 \\
\hline
\end{tabular}

Hasil langkah kedua pada tabel 2 diperoleh hasil tidak cocok, sehingga algoritma menggeser pattern sebanyak satu langkah ke kanan menuju indek berikutnya, seperti pada tabel 3 : 
Tabel 3. Penggunaan algoritma brute force langkah-3

\begin{tabular}{|c|c|c|c|c|c|c|c|c|c|c|c|c|c|}
\hline Langkah & & & & & & & & & & & & & \\
\hline Text & D & A & $\mathrm{T}$ & A & B & A & S & $\mathrm{E}$ & M & Y & $S$ & Q & $\mathrm{L}$ \\
\hline Pattern & & & $\mathrm{M}$ & $\mathrm{Y}$ & $\mathrm{S}$ & $\mathrm{Q}$ & $\mathrm{L}$ & & & & & & \\
\hline Indeks & 1 & 2 & 3 & 4 & 5 & 6 & 7 & 8 & 10 & 11 & 12 & 13 & 14 \\
\hline
\end{tabular}

Hasil langkah ketiga pada tabel 3 diperoleh hasil tidak cocok, sehingga algoritma menggeser pattern sebanyak satu langkah ke kanan menuju indek berikutnya, seperti pada tabel 4:

Tabel 4. Penggunaan algoritma brute force langkah-4

\begin{tabular}{|c|c|c|c|c|c|c|c|c|c|c|c|c|c|c|}
\hline Langkah Ke-4 & & & & & & & & & & & & & & \\
\hline Text & D & A & $\mathrm{T}$ & A & B & A & $\mathrm{S}$ & $\mathrm{E}$ & & M & Y & $S$ & Q & $\mathrm{L}$ \\
\hline Pattern & & & & $\mathrm{M}$ & $\mathrm{Y}$ & $S$ & $\mathrm{Q}$ & $\mathrm{L}$ & & & & & & \\
\hline Indeks & 1 & 2 & 3 & 4 & 5 & 6 & 7 & 8 & 9 & 10 & 11 & 12 & 13 & 14 \\
\hline
\end{tabular}

Hasil langkah keempat pada tabel 4 diperoleh hasil tidak cocok, sehingga algoritma menggeser pattern sebanyak satu langkah ke kanan menuju indek berikutnya, seperti pada tabel 5 :

Tabel 5. Penggunaan algoritma brute force langkah-5

\begin{tabular}{|c|c|c|c|c|c|c|c|c|c|c|c|c|c|c|}
\hline Langkah & & & & & & & & & & & & & & \\
\hline Text & D & A & $\mathrm{T}$ & A & B & A & S & E & & $\mathrm{M}$ & Y & $\mathrm{S}$ & $\mathrm{Q}$ & $\mathrm{L}$ \\
\hline Pattern & & & & & $\mathrm{M}$ & $\mathrm{Y}$ & $S$ & $\mathrm{Q}$ & $\mathrm{L}$ & & & & & \\
\hline Indeks & 1 & 2 & 3 & 4 & 5 & 6 & 7 & 8 & 9 & 10 & 11 & 12 & 13 & 14 \\
\hline
\end{tabular}

Hasil langkah kelima pada tabel 5 diperoleh hasil tidak cocok, sehingga algoritma menggeser pattern sebanyak satu langkah ke kanan menuju indek berikutnya, seperti pada tabel 6 :

Tabel 6. Penggunaan algoritma brute force langkah-6

\begin{tabular}{lllllllllllllll}
\hline Langkah Ke-6 & & & & & & & & & & & & & \\
\hline Text & D & A & T & A & B & A & S & E & & M & Y & S & Q & L \\
\hline Pattern & & & & & & M & Y & S & Q & L & & & & \\
\hline Indeks & 1 & 2 & 3 & 4 & 5 & 6 & 7 & 8 & 9 & 10 & 11 & 12 & 13 & 14 \\
\hline
\end{tabular}

Hasil langkah keenam pada tabel 6 diperoleh hasil tidak cocok, sehingga algoritma menggeser pattern sebanyak satu langkah ke kanan menuju indek berikutnya, seperti pada tabel 7 :

Tabel 7. Penggunaan algoritma brute force langkah-7

\begin{tabular}{lllllllllllllll}
\hline Langkah Ke-7 & & 11 & & & & & & & & & & & & \\
\hline Text & D & A & T & A & B & A & S & E & & M & Y & S & Q & L \\
\hline Pattern & & & & & & & M & Y & S & Q & L & & & \\
\hline Indeks & 1 & 2 & 3 & 4 & 5 & 6 & 7 & 8 & 9 & 10 & 11 & 12 & 13 & 14 \\
\hline
\end{tabular}

Hasil langkah ketujuh pada tabel 7 diperoleh hasil tidak cocok, sehingga algoritma menggeser pattern sebanyak satu langkah ke kanan menuju indek berikutnya, seperti pada tabel 8 : 
Tabel 8. Penggunaan algoritma brute force langkah-8

\begin{tabular}{lllllllllllllll}
\hline Langkah Ke-8 & 1 & & & & & & & & & & & & \\
\hline Text & D & A & T & A & B & A & S & E & & M & Y & S & Q & L \\
\hline Pattern & & & & & & & & M & Y & S & Q & L & & \\
\hline Indeks & 1 & 2 & 3 & 4 & 5 & 6 & 7 & 8 & 9 & 10 & 11 & 12 & 13 & 14 \\
\hline
\end{tabular}

Hasil langkah kedelapan pada tabel 8 diperoleh hasil tidak cocok, sehingga algoritma menggeser pattern sebanyak satu langkah ke kanan menuju indek berikutnya, seperti pada tabel 9 :

Tabel 9. Penggunaan algoritma brute force langkah-9

\begin{tabular}{|c|c|c|c|c|c|c|c|c|c|c|c|c|c|c|}
\hline Langkah & & & & & & & & & & & & & & \\
\hline Text & D & A & $\mathrm{T}$ & A & B & A & $S$ & E & & M & Y & $S$ & $\mathrm{Q}$ & $\mathrm{L}$ \\
\hline Pattern & & & & & & & & & $\mathrm{M}$ & $\mathrm{Y}$ & $S$ & $\mathrm{Q}$ & $\mathrm{L}$ & \\
\hline Indeks & 1 & 2 & 3 & 4 & 5 & 6 & 7 & 8 & 9 & 10 & 11 & 12 & 13 & 14 \\
\hline
\end{tabular}

Hasil langkah kesembilan pada tabel 9 diperoleh hasil tidak cocok, sehingga algoritma menggeser pattern sebanyak satu langkah ke kanan menuju indek berikutnya, seperti pada tabel 10 :

Tabel 10. Penggunaan algoritma brute force langkah-10

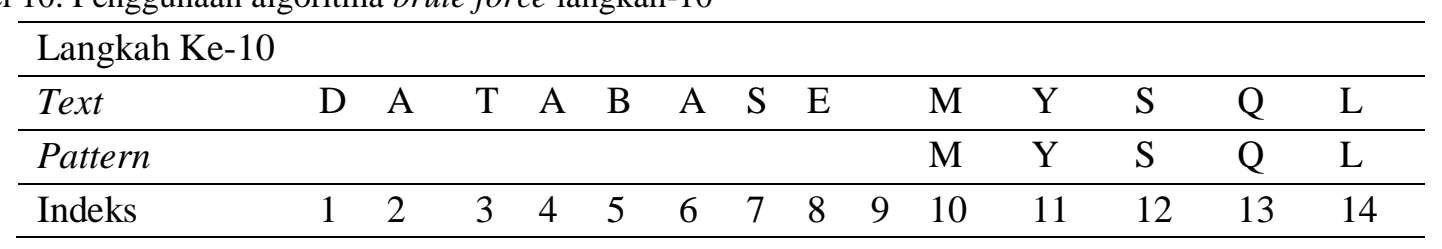

Hasil langkah kesepuluh pada tabel 10 diperoleh hasil cocok, sehingga pattern di temukan dan pencarian berhenti di indeks ke-10

\subsection{Aplikasi}

Sistem Aplikasi Kamus Istilah Bahasa Pemrograman PHP Menggunakan Algoritma Brute Force ini dibangun dengan menggunakan bahasa pemrograman dengan hasil tampilan sebagai berikut :

a. Halaman Cari Istilah, pada halaman ini pengguna diminta untuk menginputkan kata istilah bahasa pemrograman php yang diinginkan. Tampilan halaman cari istilah dapat terlihat seperti pada gambar 2: b. Halaman Tampil Istilah, Jika data ada maka akan di tampilkan semua daftar data istilah yang sesuai dengan pencarian. Tampilan halaman istilah tersajikan seperti pada gambar 3 :

c. Jika pengguna ingin menyampaikan komentar kritik ataupun saran maka mengisi isian sesuai form komentar dengan tampilan seperti pada gambar 4:

d. Halaman data daftar istilah, adalah halaman yang menampilkan semua data istilah yang ada di bahasa pemrograman PHP dengan tampilan seperti pada gambar 5:

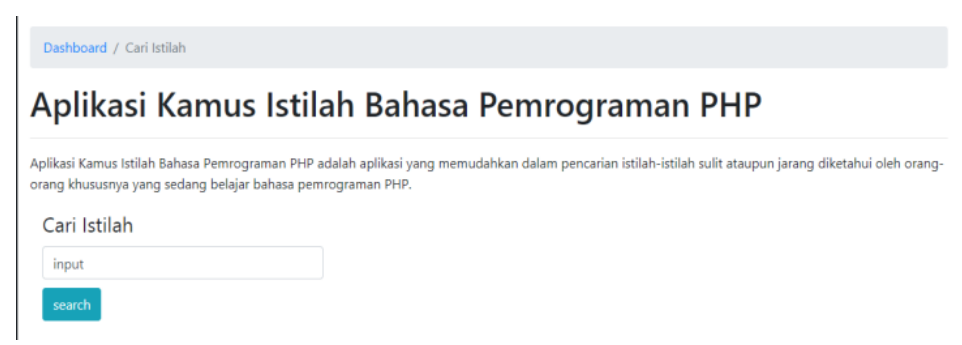

Gambar 2. Halaman Cari Istilah 


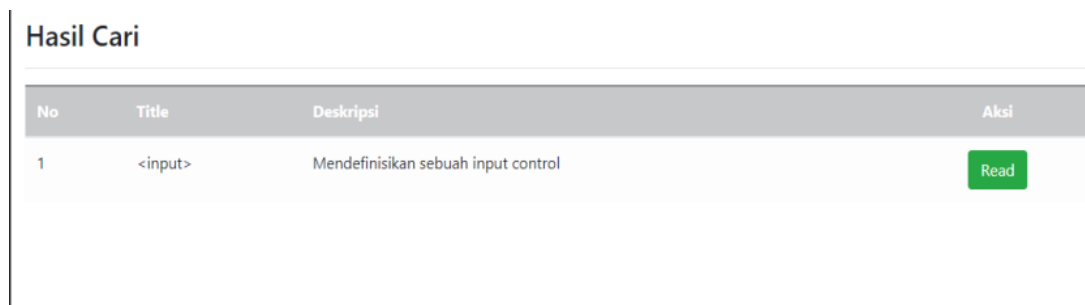

Gambar 3. Halaman Tampil Istilah

Komentar

Email
erdaniizier@gmail.com
Title
<input>
Komentar
Pengertian kurang lengkap
Submit Kembali

Gambar 4. Kolom komentar

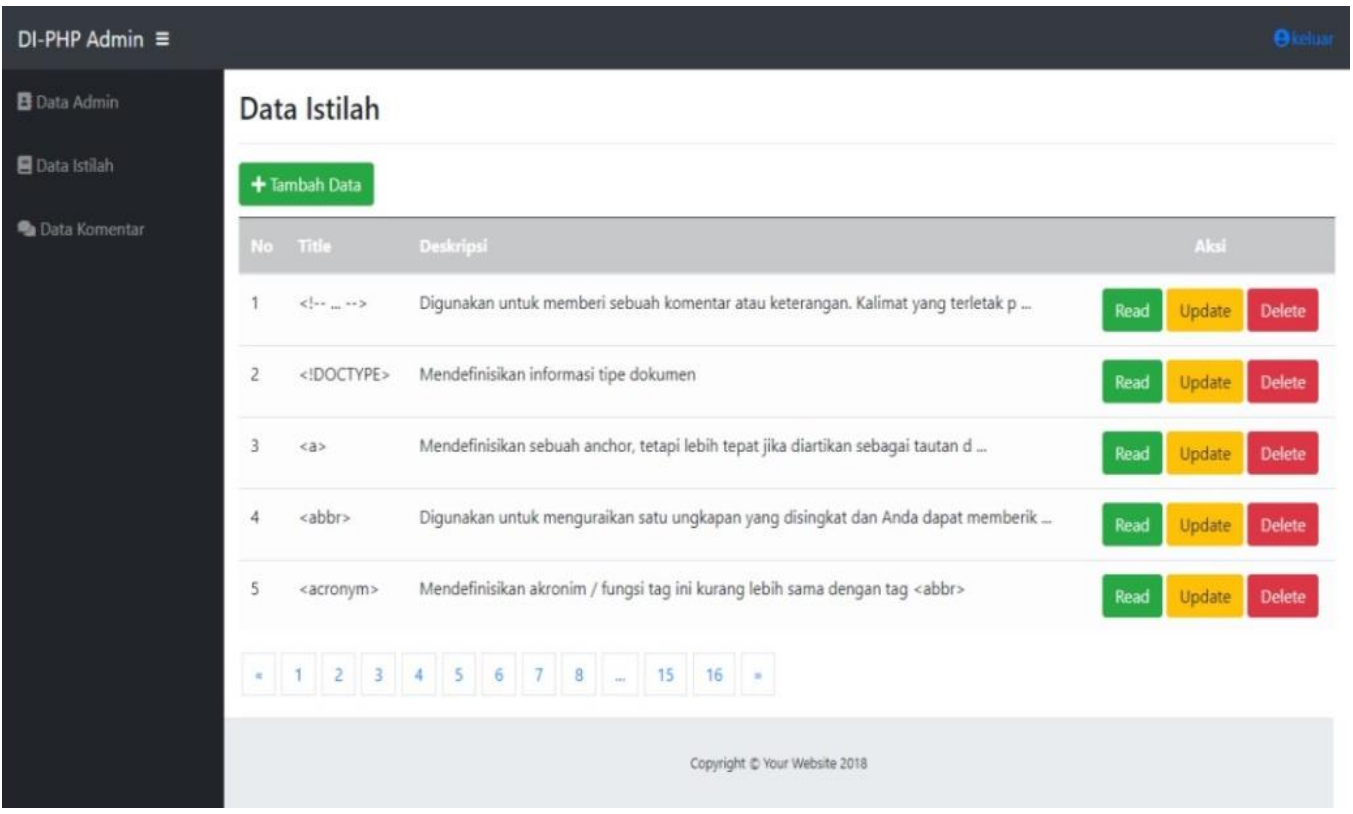

Gambar 5. Halaman data daftar istilah

\section{KESIMPULAN}

Algoritma Brute Force dapat digunakan untuk metode pencarian dengan konsep kamus. Untuk dapat melakukan proses pencarian tentang istilah-istilah dalam bahasa pemrograman php dengan mudah, praktis dan efisien. Aplikasi Kamus Istilah Bahasa Pemrograman Php (DI-PHP) dapat membantu user yang dalam hal ini mahasiswa untuk mengetahui istilah-istilah dalam bahasa pemrograman php.

\section{DAFTAR PUSTAKA}

Arfyantilta, dkk. Implementasi algoritma brute force dalam Aplikasi kamus istilah kesehatan.

Samarinda:http://jitter.widyatama.ac.id /index.php/jitter/article/view/86. 
Diakses 7 Januari 2019.

Arief M Rudianto. 2011. Pemrograman Web Dinamis menggunakan PHP dan MySQL CV ANDI OFFSET.Yogyakarta Hoetomo. 2005. Kamus Lengkap Bahasa Indonesia. Surabaya: Mitra Pelajar.

Jhonnie fadillah (2017). https://medium.com/@jhofais/mengapa -memilih-php-kelebihan-dankekurangan-php-46938854d443. Kota diakses tanggal 18 Januari 2019.

Jogiyanto,M. 2005. Analisa dan sistem informatika dan analisa dan sistem informasi. Yogyakarta. Andi offset. Diakses 7 Januari 2019.

Mesran, 2014. Implementasi Algoritma Brute Force Dalam Pencarian Data Katalog Buku Perpustakaan. Medan: https://www.researchgate.net/publicati on/313773155_Implementasi_Algoritm a_Brute_Force_Dalam_Pencarian_Dat a_Katalog_Buku_Perpustakaan. Diakses 7 Januari 2019.

Santoso,Bayu,Widia.2016. Implementasi Algoritma Brute Force Sebagai Mesin Pencari( Search Engine) Berbasis Web Pada Database. Jakarta Selatan:j ournal.stmikglobal.ac.id/index.php/sisf otek/article/download/l/pdf. Diakses 7 januari 2019.

Sarno, Riyanto, dkk, 2012, Semantic Search Pencarian Berdasarkan Konten, Yogyakarta Andi Offset

Sibero,Alexander F.K. 2012, "Kitab Suci Web Programing”. Jakarta: Mediakom. 